\title{
The Impact of the Ring Roads on the Location Pattern of Shops in Town and City Centres. A Space Syntax Approach
}

\author{
Akkelies van Nes ${ }^{1,2}$ (D) \\ 1 Department of Civil Engineering, Western Norway University of Applied Sciences, 5020 Bergen, Norway; \\ avn@hvl.no or a.vannes@tudelft \\ 2 Department of Urbanism, Faculty of Architecture, Delft University of Technology, \\ 2628 CD Delft, The Netherlands
}

check for updates

Citation: van Nes, A. The Impact of the Ring Roads on the Location Pattern of Shops in Town and City Centres. A Space Syntax Approach. Sustainability 2021, 13, 3927. https:// doi.org/10.3390/su13073927

Academic Editor: Marc A. Rosen

Received: 23 February 2021

Accepted: 25 March 2021

Published: 1 April 2021

Publisher's Note: MDPI stays neutral with regard to jurisdictional claims in published maps and institutional affiliations.

Copyright: (C) 2021 by the author. Licensee MDPI, Basel, Switzerland. This article is an open access article distributed under the terms and conditions of the Creative Commons Attribution (CC BY) license (https:// creativecommons.org/licenses/by/ $4.0 /)$.

\begin{abstract}
This contribution demonstrates how inner ring roads change the location pattern of shops in urban areas with the application of the space syntax method. A market rational behaviour persists, in that shop owners always search for an optimal location to reach as many customers as possible. If the accessibility to this optimal location is affected by changes in a city's road and street structure, it will affect the location pattern of shops. Initially, case studies of inner ring road projects in Birmingham, Coventry, Wolverhampton, Bristol, Tampere, and Mannheim show how their realisation affect the spatial structure of the street network of these cities and the location pattern of shops. The results of the spatial integration analyses of the street and road network are discussed with reference to changes in land-use before and after the implementation of ring roads, and current space syntax theories. As the results show, how an inner ring road is connected to and the type of the street network it is imposed upon dictates the resulting location pattern of shops. Shops locate and relocate themselves along the most spatially-integrated streets. Evidence on how new road projects influence the location pattern of shops in urban centres are useful for planning sustainable city centres.
\end{abstract}

Keywords: ring roads; centrality; road building; space syntax; shopping areas; movement routes; urban change

\section{Introduction-The Inner Ring Road and Urban Change}

Present and past constructions of roads and streets presumably influence future city growth. Their order and structure in general exist longer than buildings. Up until now, the average age of a street is about 1000 years, while the usage of urban space along streets is changing almost continuously. The pattern of functions inside buildings can change fast, whereas the building itself might remain as it is for about 100 years [1]. When changing the street and road pattern in a built environment, this change must have some kind of effect on future buildings and also on the functions they actually have or will assume. Evidence on the relationship between road building and location pattern of shops in city centres is, thus, needed for achieving the UN's sustainable development goal number 11: enhancing sustainable cities and communities.

This contribution assesses the interrelationship between road building and urban changes through investigating how inner ring roads change the dispersal of shops. The relationship between road construction and spatial development in urban areas is at present not adequately understood. Most investigations treat these two aspects separately. Engineers tend to occupy themselves with the question of how larger road projects produce changes in traffic flow. Their interest in this question distinctly echoes their concern with building road networks that are able to carry an expected traffic flow, and with origin and destination traffic flow models [2]. Architects and urban planners, however, are often occupied with solving the formal problem of implementing various functions required in urban areas. Their focus is mostly on the urban blocks that are between the streets and roads in a built environment. 
Implementing ring roads and separating vehicle transport from pedestrians was considered an easy solution to divert traffic from city centres, solve heavy traffic problems in old city centres, and to reduce traffic accidents between vehicles and pedestrians. However, in many cases, ring roads contributed to the reconfiguration of city centres to varying degrees. Likewise, the second half of the 20th century's planning regulations, which focused on facilitating car accessibility and traffic safety, contributed to distorting the natural movement and the natural optimisation process of self-grown, well-functioning city centres.

Present knowledge about road building and urban change results primarily from empirical studies that were carried out before and after major changes in a transportation system [3]. The time span is usually very short. There are several arguments as to why the effects of inner ring roads on urban street networks lend themselves to close examination. In most cases, related projects are well defined, because the ring road project is finished when the ring is closed. Many inner ring roads encircle a town centre in its entirety. Usually, it takes 20 to 30 years to build an inner ring road. It, thus, seems rather easy to identify the specific changes they cause.

How do inner ring roads change urban areas, and what kind of changes can be predicted? When revealing the planning documents from cases with an inner ring road, information can be found on the intentions for the implementation, and the political and planning processes. In most cases, the inner ring road was implemented to relieve the town centre from through traffic. Most ring roads are imposed onto an existing road network. Although most ring roads were constructed between 1955 and 1990, many politicians and planners still consider a ring road to be a solution for dealing with heavy traffic problems in urban centres. In some towns, a ring road might solve this problem. In others, its implementation could lead to unpredicted effects on the town centres' street life and economic activities. The alternative indicates how important it actually is to gain systematic insight into how ring roads affect spatial and socio-economic aspects of built environments.

From an economical point of view, shops and retail owners obviously have to reach their potential customers [4]. An optimal (i.e., market rational) approach requires that shop and retail owners locate their business where the highest rates of movement of potential customers in a built environment's street network occur. Ring roads change the movement pattern from everywhere to everywhere else in a built environment. If an inner ring road reduces or increases accessibility for potential customers, then their location pattern has to be influenced accordingly.

The present research refrains from identifying intentions and purposes for which ring roads are built from the planning processes. Likewise, it does not identify the actors involved in planning processes and implementation. The present inquiry focuses on the moment after a ring road's implementation, and how, precisely, a development of this sort can be analysed in terms of a street network's spatial configuration and land-use in a built environment. The direction of this inquiry is to analyse the spatial configuration of the street network and correlate the results from the spatial analyses with the location pattern of shops before and after the implementation of the inner ring roads of six different town and cities. The purpose is to test out the theory of the natural movement of economic processes proposed by Hillier and his colleagues on different types of built environments. The meaning is to reveal how sensitive shops are to spatial configurative changes in terms of spatial integration and accessibility. As it turns out, the spatial configuration of the street and road network matters for a natural urban transformation process. Thus, the road engineer is, in many ways, the urban designer on a large scale.

\section{Literature Review Regarding Ring Roads}

\subsection{Types of Ring Roads and Their Various Functions}

In a $\mathrm{PhD}$ research, the conceptual framework of the various types of ring roads were discussed [1]. A ring road is defined to be a part of a built environment's main routes structure. It encircles a town or city's central core. The kind of ring roads examined in this 
research are those integrating into an existing street structure, creating new movement routes. In general, there are two types of ring roads; the highway and the boulevard ring road.

A highway ring road is designed mostly for car traffic with little to almost no space for pedestrian movement. The label 'motorway' is often used. A motorway is more directly connected to other roads than a highway. A highway consists of flyovers at its junctions. However, the distinction between highway and motorway is not always certain. There exist motorways with flyovers and highways with direct connections to other roads at their junctions [1]. In the present context, the label 'highway' is used. The degree of connectivity to the street network on which the ring road was imposed upon is low. In most cases, a highway ring road is connected to the main routes of a city or town. They consist of curves and junctions for carrying car traffic at a certain speed, with the purpose of reaching different parts of a built environment effectively.

A boulevard style ring road has sidewalks and is mostly well connected to all streets of the street network it is imposed upon. The 'boulevard' was originally made with the purpose of recreation and promenade. Many boulevards replaced old bastions and city walls in European towns and cities. The concept 'avenue' is also used. In the United States, avenues were primary traffic streets while boulevards were the green connectors of parks in a built environment's periphery. As car traffic grew, the boulevards slowly changed their character into general traffic arteries [5]. Since the differentiation between avenue and boulevard is not certain, the label 'boulevard' is used. Some of the boulevard ring roads have tree-rows.

Sometimes there are hybrids between these two types of ring roads. There exist boulevard ring roads with few, as well as highway ring roads with many connections to their vicinity [1]. Seemingly, a precise distinction between these two types is difficult to assess intrinsically. In terms of extrinsic properties of space, the difference between a highway and boulevard ring road can be defined in terms of their degree of connectivity to the surrounding street network.

The main purpose of a ring road is to relieve town centres from cross traffic. It is meant both to divert traffic that has no business crossing through town centres and to redistribute traffic bound in and out of town centres. As intended, heavy transport should be led away from town centres, and the flow of car traffic should be dispersed via distribution roads into central areas. According to a road engineer's main intention, a ring road should improve the vehicular access to a town centre and it should offer better car traffic flow through the town as a whole [6]. Ring roads built after the Second World War had to accommodate the anticipated explosion in the growth in vehicular traffic. At the end of the 1950s, a ring road was regarded as a solution for the distribution of large numbers of cars through urban areas [7]. Furthermore, a ring road was believed to open up new opportunities for pedestrian friendly streets in a town centre, areas almost free from heavy car traffic $[1,8]$.

\subsection{Two Contradictory Views on the Relationship between Road Building and Land-Use}

In 1960, Mr. Colin D. Buchanan was appointed by the British Minister of Transport to make a study on the long-term development of motor traffic in urban areas and its effects on cities. This report, known as 'The Buchanan report', argued that most of the European towns and cities had a street structure inadequate to face the predicted explosive rise in car traffic.

The report's understanding of land-use assumed, in particular, that 'the function of the network would be to serve environmental areas and not vice versa' [8] (p. 60). Apparently, this means that a high number of different land-uses in town centres favours intense traffic of both people and cars. The type of land-use is, thus, taken to be an attractor for movement. The report takes urban environments of high quality to be safe to move through and to be free from traffic noise and pollution. However, there is little understanding of how land-use occurs, such as how retailers and shops establish themselves along the urban 
street and road network and how they respond to how people move, whether by car or by foot.

The Buchanan report did not consider the idea of ring roads as a means to relieve town centres from vehicular traffic. The ring road was taken to be a road constructed for its own sake, and to organise traffic away from the town centres. Therefore, the report proposed a hierarchic distribution of different kinds of road distributors, which should canalise movements from locality to locality. The way roads are planned and constructed in European towns and cities is still influenced by the Buchanan report [9]. A few examples on existing national road and street building guidelines are the 'SCAFT rapporten' for the Scandinavian countries [10], 'ASVV' for the Netherlands [11], HBS (Handbuch für die Bemessung von Strassenverkehrsanlage) for Germany [12], and MfS (Manual for Streets) and DMRB (Design Manual for Roads and Bridges) for the UK [13]. The most recent versions of these guidelines have strategies for enhancing pedestrian friendly streets in town and city centres. However, the guidelines for enhancing a hierarchic distribution of streets and roads in line with the Buchanan report is still present in all these guidelines.

The Buchanan report was aware of the role of street to 'give access to buildings, to give light and air and that they are setting for architecture and they are backbone of the everyday surroundings for many people' [8] (p. 73). However, its understanding of streets' role correlates little with the proposed solutions for central shopping areas, where pedestrian movement and car traffic are separated. The Buchanan report's proposal to distribute different kinds of roads hierarchically was as inappropriate as the city engineers' ideas regarding the relationship between street network and distribution of shops. As it turned out, those large road plans and planned centres did not function as they were supposed to [1].

In contrast to the Buchanan report, the other view states that the spatial configuration of the street and road network generates attraction [14] (p. 103). Bill Hillier and his colleagues at the space syntax laboratory at the University College London propose that there is a relationship between the physical form of cities and the economic processes taking place within them. According to Hillier, these aspects are interrelated by space. The relevant processes involve reciprocity; i.e., they depend on each other [15] (p. 42). Moreover, Hillier, Penn, Hanson, Grajewski, and Xu have recognised spatial configuration, movement, and attractors as three determinants of the way in which shops situate themselves within the urban network. First of all, shops locate themselves along streets where most people move. Apparently, shops tend to become attractors for the people's urban movement. Attractors and movement may influence each other, but they do not influence the spatial configuration of the urban street and road network. On the other hand, the street and road network seem to influence movement and attractors [16] (p. 31). This process is named 'the theory of natural movement' or later the 'theory of natural movement economic process' [1]. These theories are able to offer positivistic explanation models on the relation between cause and effect [17].

Urban centrality is, thus, defined not as a state, but as a process with both spatial and functional aspects. As Hillier writes: 'Successful life centres require both a global position in the settlement and compact and inter-accessible local layout conditions. This is the basics shape of centrality' [14] (p. 119). A vital shopping street, thus, depends on a high number of street connections in its vicinity, and this vicinity must consist of a high density of the street networks within a short metric distance. If these spatial conditions change, the location of economical centres will change too. Figure 1 illustrates these two contradictory views on the relationship between spatial configuration of the road and street network, movement, and attraction. 


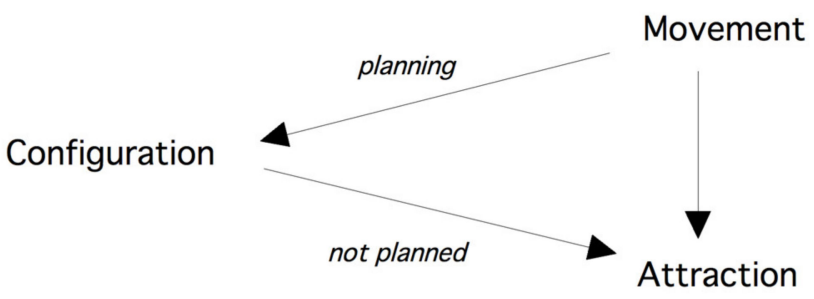

The Buchanan Report

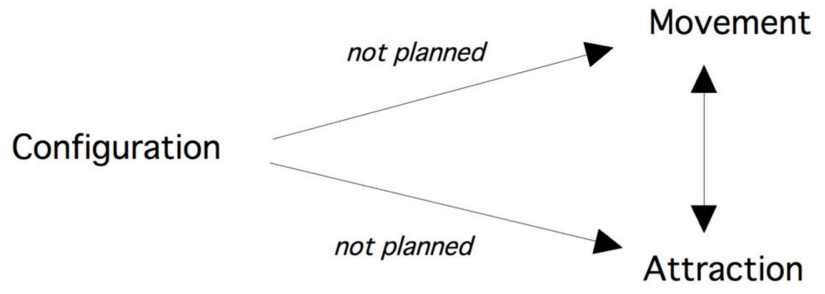

Figure 1. Two contradictory views on the relationship street network configuration, attraction, and movement.

This study differentiates from other studies on the impact on road building and urban change in the following way. First, a detailed registration of land-use inside buildings before and after the implementation of large road projects are carried out. The time span for the before and after situation is large, which is over 60 years. The application of the space syntax method in a before and after situation of large road projects over such a large time span, juxtaposed with the dispersal of land-uses inside buildings is not done earlier. Moreover, this study tests out the robustness of the theory of the natural movement economic processes proposed by Hillier and his colleagues. In other related space syntax studies, the empirical support of this theory is carried out in a present situation. If the location pattern of shops is dependent on the spatial configuration of the street and road network, then it is worth testing out how spatial configurative change affect the location pattern of shops. The next step is to reveal the results from specific case studies.

\section{The Method of Investigation}

For this inquiry, the central areas of Wolverhampton, Coventry, Birmingham, and Bristol are used. Mannheim and Tampere are used as atypical cases. The condition for selecting these towns was based on the accessibility of historic data such as detailed maps and street directories for the location pattern of shops. Considering the situation of all six cases, before their inner ring roads were built, the shops as well as the street network's configuration were attractors for movement towards and within the centre of town. If the inner ring road changes the configuration of the street and road network, then it is worth noting whether the distribution of shops changes or not. Due to lack of sales data from shops, and data on pedestrian and car traffic flow rates from the past, the emphasis lies on the relationship between aspects of attraction (shops) and spatial configuration of the street and road network. More precisely, the present work focuses on the land-use and spatial aspects of how ring roads change the dispersal of shops.

Investigating the spatial and land-use changes of built environments requires one to have access to data on the location pattern of land-use before and after the implementation of a ring road, and maps from the previous situation. The information on the location of land-use was found in old street directories, address books, and historic maps at the various local archives. Regarding the shops, no differentiations were made between various types of shops. The focus was on the function 'shop' and their location. Reliable data on traffic flow (pedestrian and vehicle transport) from the situation before the implementation of the ring road could not be found (as expected) for all six towns and cities.

The space syntax method consists of calculating the degree of a street's spatial integration in relation to all other streets in a built environment. The classical space syntax method consists of calculating various degrees of spatial integration in terms of the number of direction changes from each street segment to all others. Hence, a low number of direction changes from one street to all others indicate high integration values. In order to visualise the degree of integration, colour codes are used to represent the various integration values of the streets. The red and yellow lines show the $10 \%$ most integrated streets, while the dark 
blue lines are the most segregated ones. Each street's topological relationship to all other streets in a before and after situation is calculated. Here, the 'to-movement' potentials of a street network are calculated, based on axial sight lines. Only global integration analysis is used in this research due to the size of the study area in all six cases.

The most recent spatial calculations in space syntax takes angular weighting between street segments and segment length into account. The angular choice calculations show the 'through-movement' potentials [18], whereas the segment integration shows the 'tomovement' potentials [19]. The focus of this research was to reveal the change in the 'to-movement' potentials as an effect of the ring road. As research has shown, streets and roads with a high level of to-movement potentials tend to have shops located along them $[14,15,17,18]$. Therefore, the angular choice analyses were left out. The only thing the choice analyses shows is that the ring road becomes a part of the main route network of the city. Moreover, the classical axial analyses with only topological distance show the same results as in the segment integration analyses. Therefore, the results from only the axial analyses is shown.

The classic global axial integration analysis from Hillier and Hanson [20] also happened to show the best correlation between spatial integration and location pattern of shops in an investigation on how new bypass roads affect local centres in four Norwegian towns [21]. Likewise, the global axial integration analysis has been applied throughout the years for making impact assessments of various road alternatives on existing urban centres [22,23].

The following formula is used to calculate axial global integration $(I)$ of an axial line (i):

$$
I_{i}=\frac{2\left(n\left(\log _{2}\left(\frac{n+2}{3}\right)-1\right)+1\right) /(n-1)(n-2)}{2\left(\left(\frac{\sum_{j=1}^{n} d_{i j}}{n-1}\right)-1\right) /(n-2)}
$$

Here, the total depth to all other axes is calculated in term of the total number of direction changes. The $n$ is the number of axis and $d_{i j}$ is the least number of direction changes between two axis $i$ and $j$. The greater the number of direction changes $\left(d_{i j}\right)$ between the street axes, the lower the integration values becomes.

While an integration analysis measures dynamic centrality, a 'two step analysis' shows how much of a local area is covered by streets, which are two directional changes away from a particular street. A high number of streets with two direction changes away within a short metric distance indicate a significant shopping street. Often, shopping streets can be found within two direction changes in a neighbourhood [24]. Long streets do not impact the disposition of shops. The compactness of a reachable area impacts their distribution. Inter-accessibility is at issue in this respect [14] (p. 119).

Due to context independency and a high degree of falsifiability, the space syntax method can be applied to all types of built environments [17]. Regarding market rationality, human intentions are unambiguous. Here in this case, it is about profit maximising and the ability to reach as many customers as possible. Therefore, the location pattern of shops and retail can be predicted based on spatial configurative changes of the urban street and road structure with the application of space syntax.

The results of the various space syntax analyses can be juxtaposed with the actual distribution of shops. The changing distribution of localities before and after a ring road is built is done with space syntax analyses of a before and after situation.

As Coventry and Bristol were heavily bombed in 1940 [25,26], a registration of landuse inside buildings dating from 1955 is likely to give a distorted picture of the situation before the ring road's construction. However, a registration of land-use in all cities and towns was carried out in 1940 and 1955. The land used for buildings was categorised as follows: shops, pubs, religious buildings, leisure activities (sport, theatre, cinema, library), schools, universities, offices, industrial areas, and railway stations.

All four UK towns and cities in this inquiry managed to finish a map of their centres before World War II broke out. Due to strict copyrights rules from archives in the UK, it 
was impossible to obtain more than an A4 copy of the maps scaled at 1:10000 of these towns. They all date from around 1940 and 1955. Hence, only the area around the centre and the vicinity of the inner ring road could be analysed. To make an exact comparison of the spatial configurative changes in a before and after situation, the same size of the area was recorded in the after situation for all cases. Some of the UK towns and cities have large divisions between pedestrian and vehicle routes. Therefore, separate space syntax analyses were made for the pedestrian routes for all four cases.

Mannheim and Tampere are used as atypical cases in this inquiry for testing out how ring road affect the street network integration and the location pattern of shops in cities with strict orthogonal street patterns. The aim is to check out, to what extent, the results from the spatial analyses of Mannheim and Tampere comply with the results from the model studies.

Fortunately, all six cities and towns in this inquiry possess a rich photographic documentation of most of their streets before the World War II. According to the cities' and towns' various street directories from the 1930s, most of the shopping streets correspond to the old pictures found in the local town and city archives. Other functions such as pubs, post offices, industry, churches, town halls, clubhouses, theatres, cinemas, leisure centres, hotels, and banks can be identified on old and new maps scaled 1:1250. For an exact registration of the placement of shops, old street directories were a useful source.

The data gathering after the implementation of the ring road was carried out from 1997 to 2001. The reason is that after the millennium, new plans were discussed for making improvements in line with the compact city movement and Local Agenda 21 (LA21) requirements $[27,28]$. In most cases, the inner ring road was finished in the middle of the 1980s, and 15 years later the land uses of buildings had settled or adjusted to the new situation.

In all six cases, the inner ring road has been imposed upon different kinds of street networks. Using the space syntax method and comparing the results of its application with actual land use changes made it possible to explain how inner ring roads affect the location pattern of shops in town and city centres.

\section{The Results from the Analysis of Six Case Studies}

Firstly, the results from the four UK towns and cities are presented. All of them are typical cases with an extreme growth period during the industrial revolution. Then the results from the two atypical cases are presented. The ring roads in all six cases were imposed upon an existing urban fabric, where several buildings were demolished and pedestrian pathways street patterns were changed a lot.

\subsection{The Analyses of the Four UK Towns and Cities}

After all, a ring road changes the spatial configuration of a street network. How a ring road is imposed upon an existing street network pertains to the sense in which the ring road affects the location pattern of shops. The analysis of Bristol seems to indicate two things: the difference between the highway and the boulevard standard on a ring road, and how the ring road is connected to the surrounding street network.

Figure 2 shows the spatial integration analyses of the street network (left) and the pattern of land use of buildings (right) for Coventry and Wolverhampton around 1940. The red and orange lines represent the highest integrated streets, while the blue lines represent the most segregated ones. The black pattern of shops can be clearly seen from the land-use registration. The central shopping areas are located along the most integrated streets, which are the red lines. The shops have a linear location pattern in both cases. 


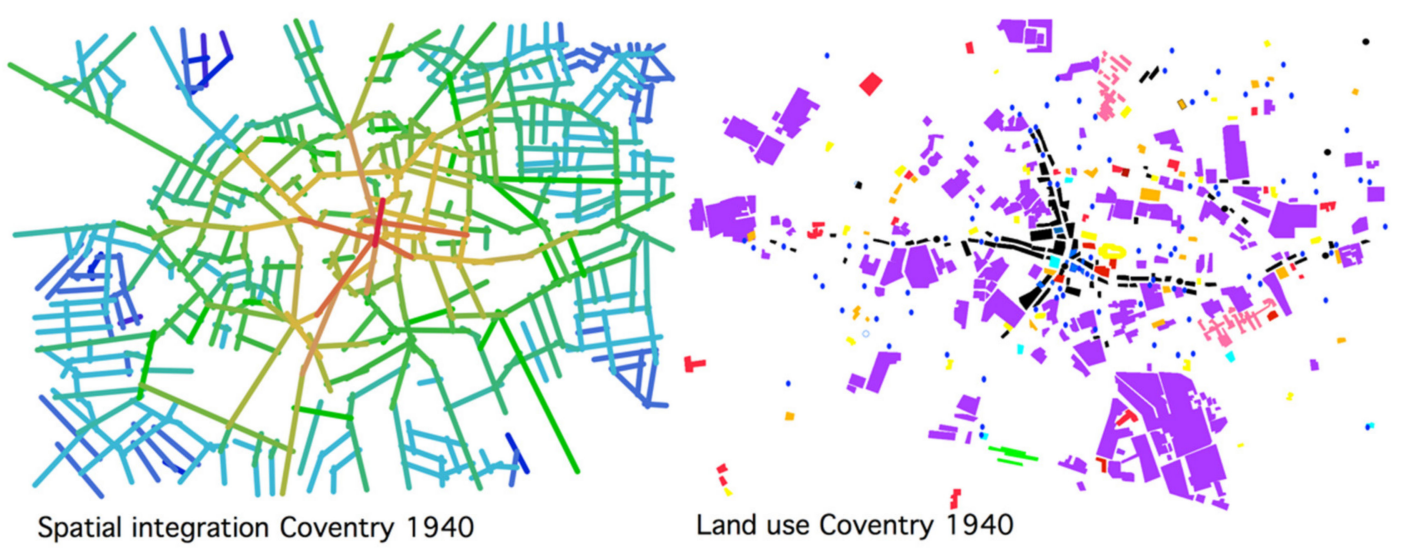

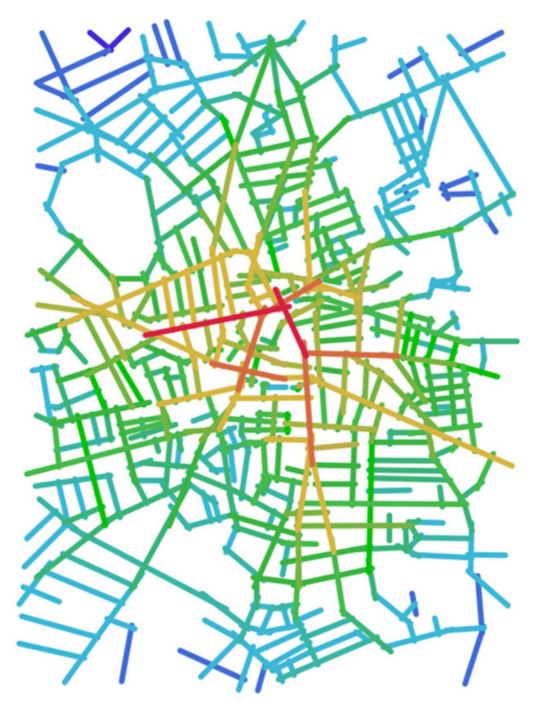

Spatial integration Wolverhampton 1940

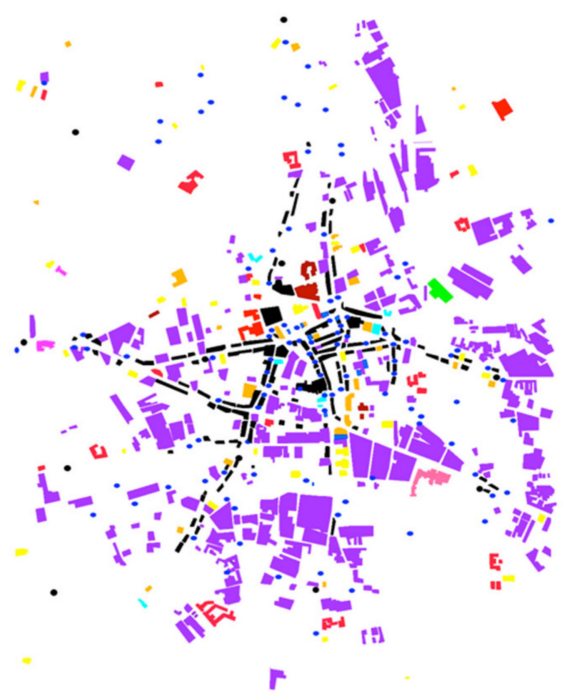

Land use Wolverhampton 1940
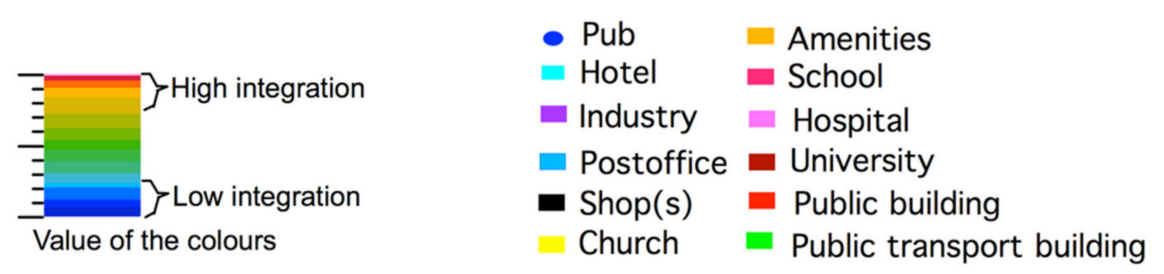

Figure 2. The spatial integration of the street network (left) with the dispersal of land uses of buildings (right) in 1940 of Coventry and Wolverhampton.

Figure 3 shows the spatial integration analyses of the street network (left) and the pattern of land use of buildings (right) for Birmingham and Bristol. Except for Birmingham, the central shopping areas are located along the most integrated streets, which are the red lines. The shops in Birmingham are located along the second-best integrated streets with the highest density of direct connected streets to its vicinity. Bristol has two city centres, one large in the east and one smaller located in the west (St. August parade). These two centres are 500 metres from each other and are both linked by the highest integrated Castle Street.

The shops have a linear location pattern in all four cases. The shops are located along the $5 \%$ highest integrated streets (coloured in red and orange). Thus, there is a correlation between the spatial structure of the street network and the dispersal of shops in all the analyses of 1940 . 


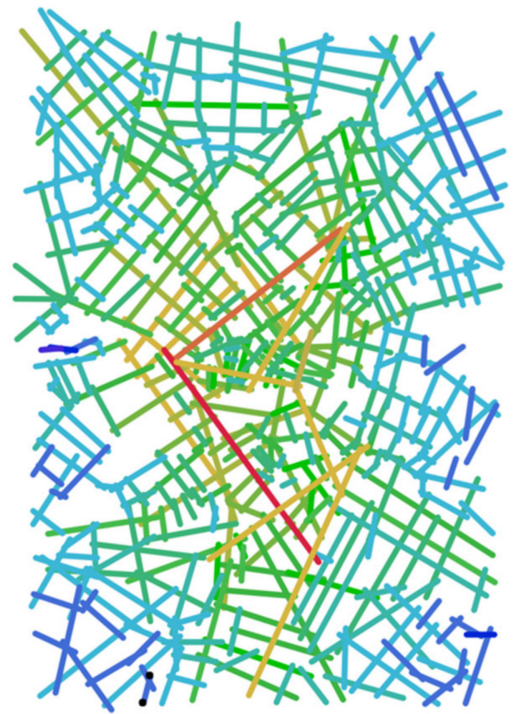

Spatial integration Birmingham 1940

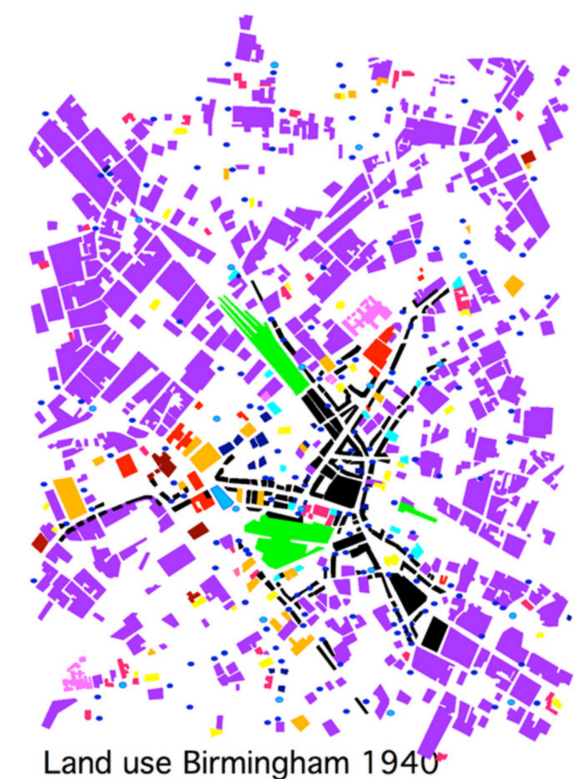

Land use Birmingham 1940"

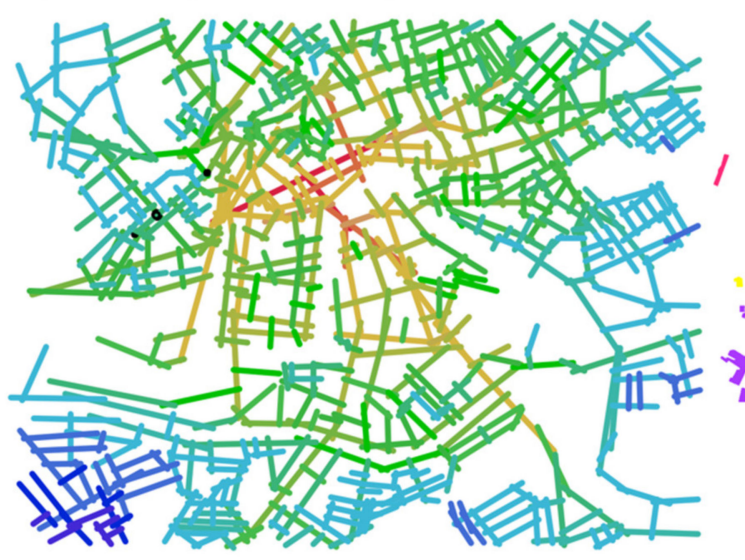

Spatial integration Bristol 1940

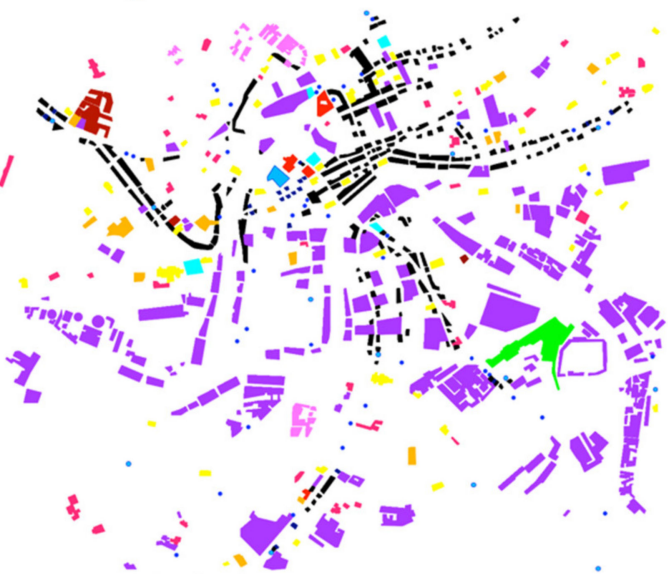

Land use Bristol 1940

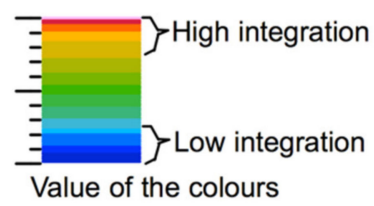

$\begin{array}{ll}\text { - Pub } & \text { Amenities } \\ \text { Hotel } & \text { School } \\ \text { Industry } & \text { Hospital } \\ \text { Postoffice } & \text { University } \\ \text { - Shop(s) } & \text { Public building } \\ \text { Church } & \text { Public transport building }\end{array}$

Figure 3. The spatial integration of the street network (left) with the land uses of buildings (right) in 1940 of Birmingham and Bristol.

Figure 4 presents spatial integration analyses of the vehicle (left) and pedestrian routes (middle) of Coventry and Wolverhampton in 1997 after the implementation of the ring road and the dispersal of land use of buildings (right). In comparison with the situation in 1940, the highest integration values tend to move to the well-connected crossroads between the ring road and the town centre in the vehicle routes analyses. Regarding the pedestrian route analyses, the central streets have a high level of integration, but the areas outside the ring road are less integrated. This has affected the location pattern of shops (coloured in black), that is changed from a linear to a convex clustered location pattern. 


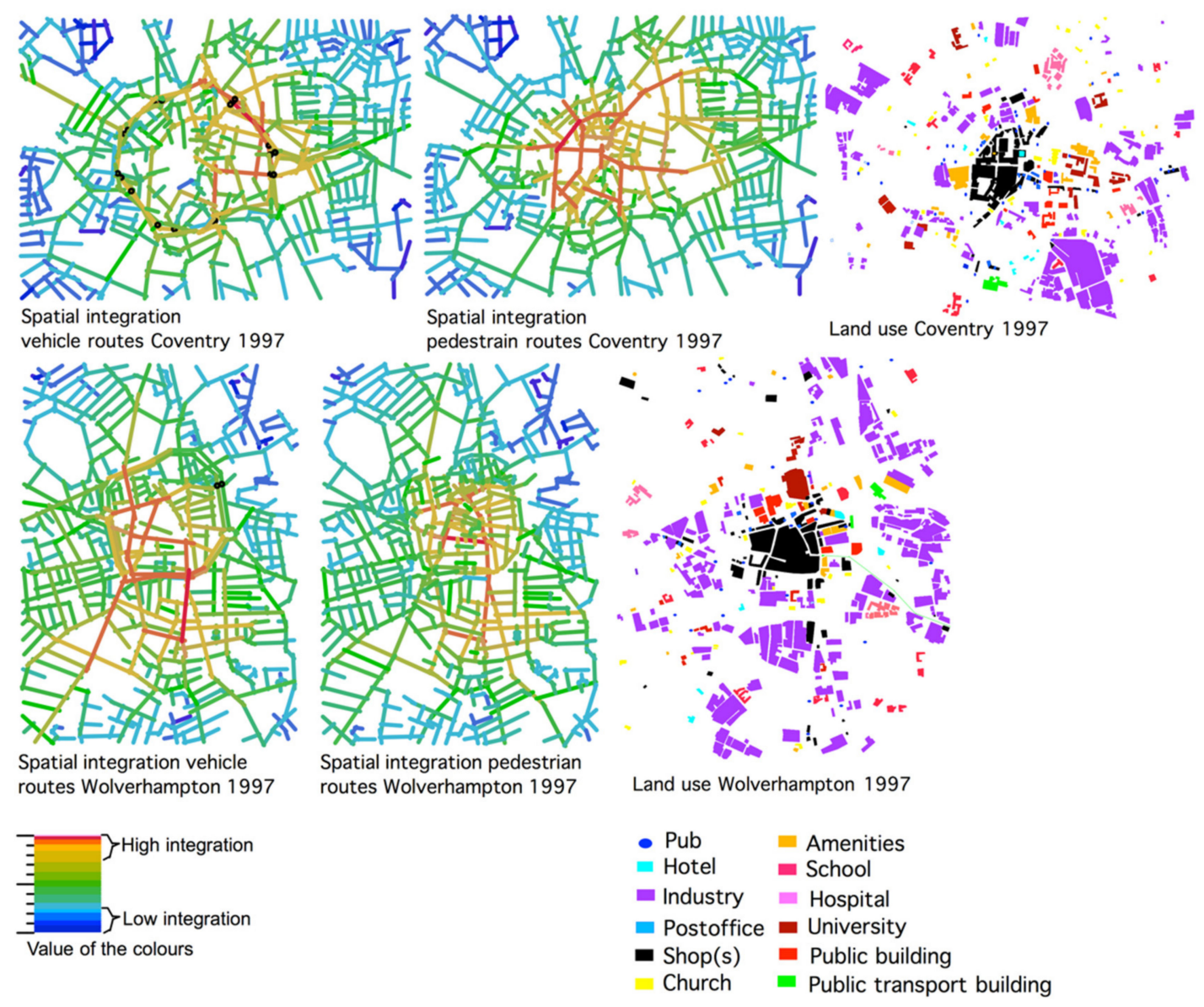

Figure 4. The spatial integration of the street network (left and middle) and the land uses of buildings (right) in 1997 of Coventry and Wolverhampton.

Figure 5 presents the spatial integration analyses of the vehicle (left) and pedestrian routes (middle) of Birmingham and Bristol in 1997 and 1998 after the implementation of the ring road with the dispersal of land use of buildings (right). The ring road was imposed upon the old main squares of both cities. In the case of Birmingham, integration reduced and shops disappeared from the old Bullring Square. Conversely, no changes occurred in the integration values and the location pattern of shops of the square St. Augusts parade in Bristol. They have kept their linear location pattern. This part will be revealed with the 'two step analysis' method later in this section.

Here again, the location pattern of shops has changed from a linear to a convex clustered pattern. The areas outside the ring road have become segregated, except for the Western part of Bristol. Interestingly enough, one of Bristol's two centres has still kept its linear location pattern of shops. It is located in the area where the ring road has a boulevard standard that is well-connected to all streets in the vicinity. In all other cases, the black coloured pattern of shops has changed from a linear to a more convex clustered location pattern.

In comparison with the situation in 1940, the ring road in Coventry and Birmingham made the streets in the city or town centre appear more segregated in the 1997 analyses than in 1940. Whereas in Wolverhampton and Bristol, the vital shopping streets have moved slightly towards the streets with direct connections to the ring road. As the 1997 and 1998 analyses demonstrate, the highest integration values tend to move to the well-connected crossroads between the ring road and the town or city centre. 


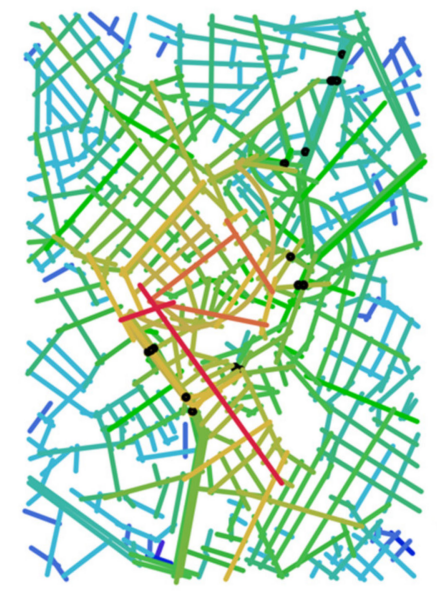

Spatial integration vehicle routes Birmingham 1997

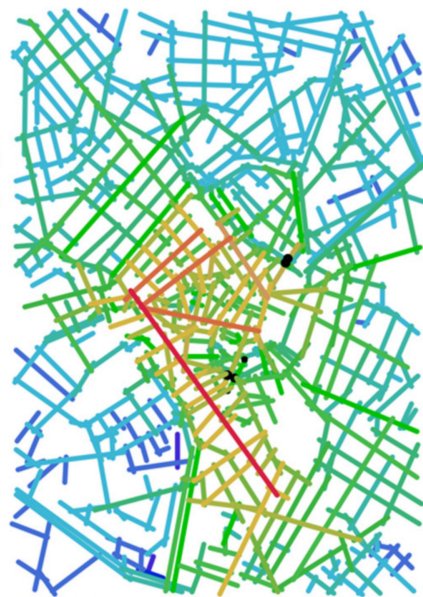

Spatial integration pedestrian routes Birmingham 1997

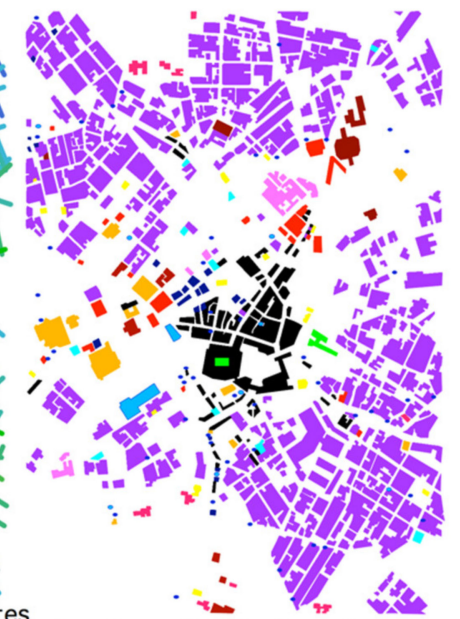

Land use Birmingham 1997

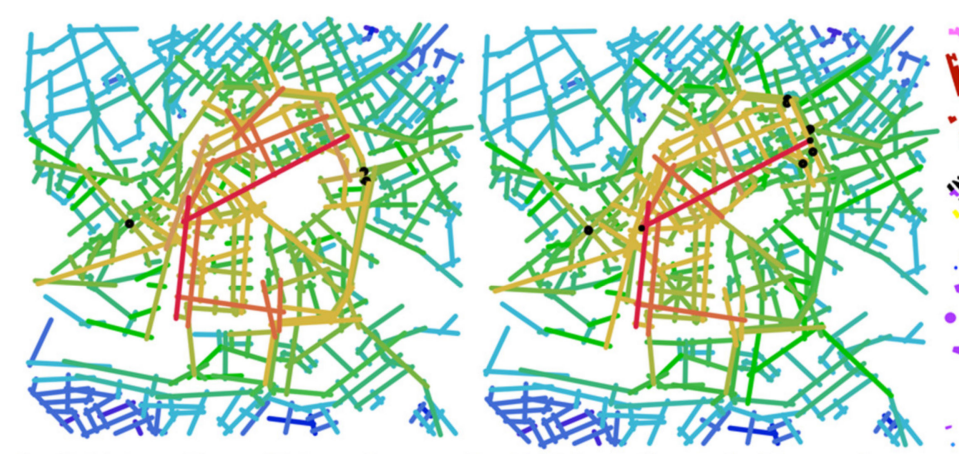

Spatial integration vehicle routes Bristol 1998

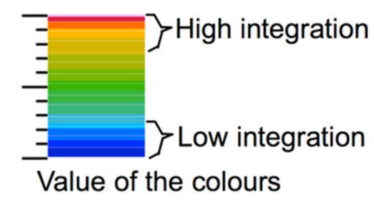

Spatial integration pedestrian routes Bristol 1998

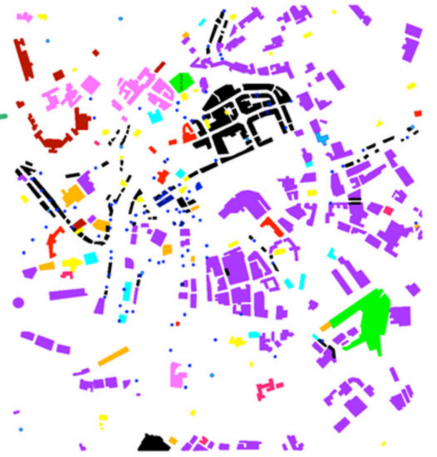

Land use Bristol 1998

- Amenities

- School

- Industry Hospital

- Shop(s) Public building

Church Public transport building

Figure 5. The spatial integration of the street network (left and middle) with the land uses of buildings (right) in 1997 and 1998 of Birmingham and Bristol.

Comparing the results from the spatial analyses of the pedestrian with the vehicle routes network for all four UK cases, the most integrated streets are almost the same, except in the case of Coventry. At present, the movement routes for pedestrian and vehicles through most of Coventry's town centre and the ring road's vicinity are separated from one another.

The next step is to reveal how the inner ring roads affected the local catchment area of the main shopping streets of all four UK cases. Figure 6 shows the extension and the spatial structure two direction changes away from the vicinity of all the main shopping streets in the four UK cases. It is obvious that the ring road has cut off the extension of all those streets where the ring road has a highway standard in the 1997 and 1998 analyses. In the case of Coventry, the modern town centre also contributed to a reduction of the topological and metric extension of Hereford Street in the 1997 analyses. In the other three cases, the pattern of the lines has become slightly more compact and convex than in the 1940 analyses. Correlated with the pattern of shops, the shopping areas have changed from a linear location pattern to a convex one. 


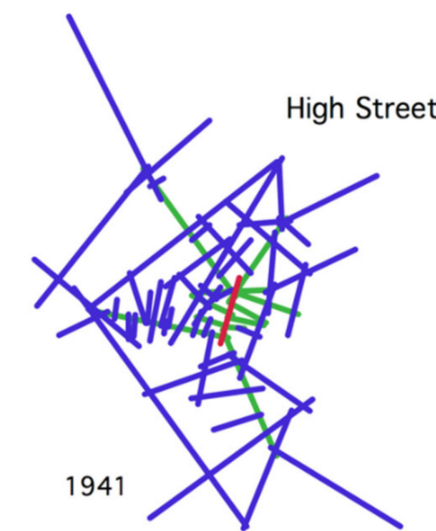

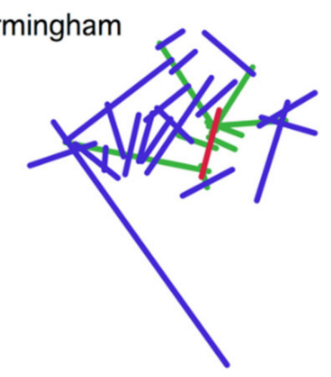

1997 vehicle routes

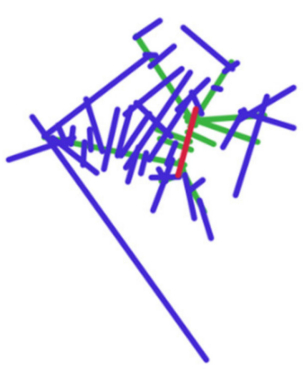

1997 Pedestrian routes

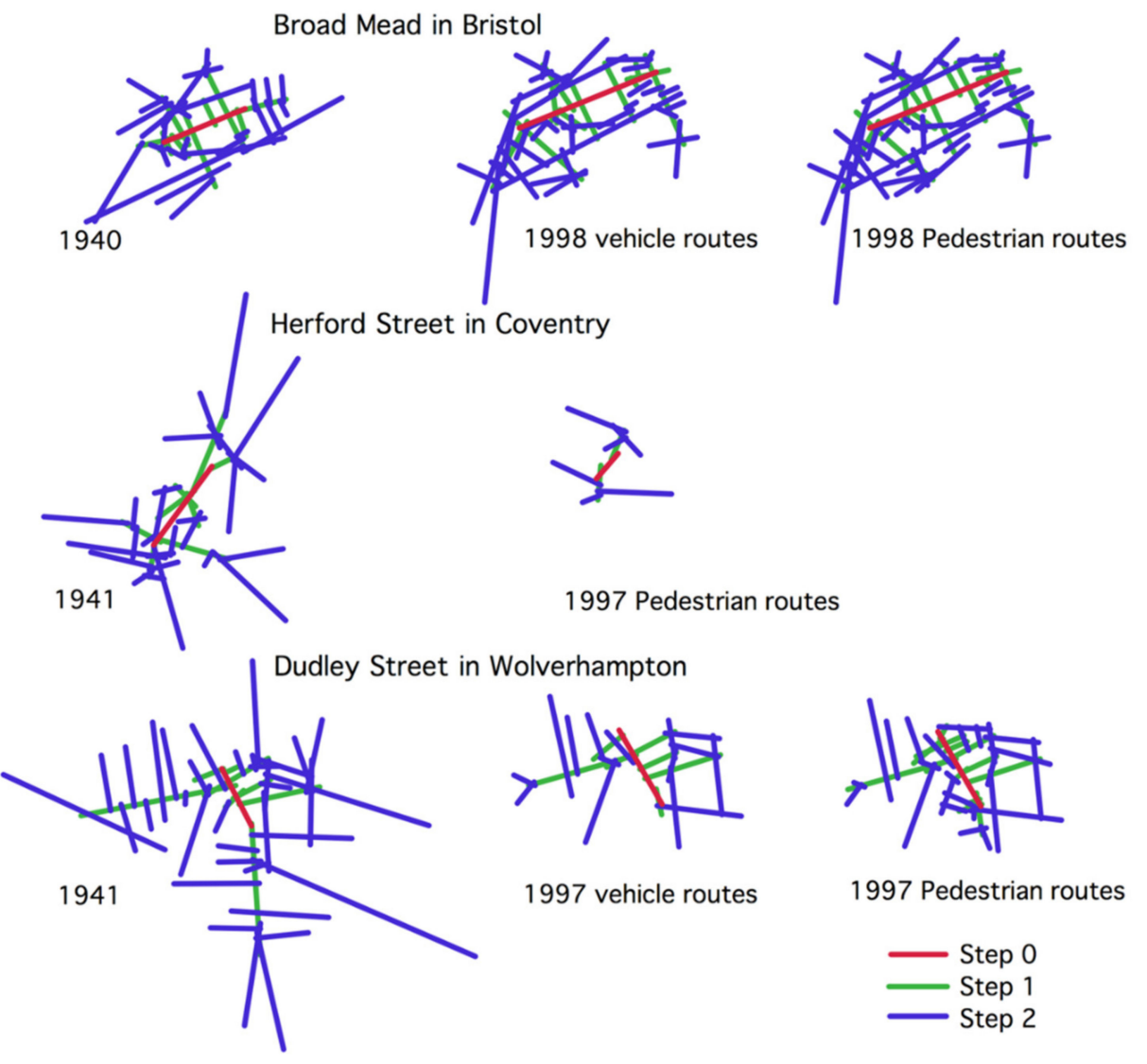

Figure 6. Two steps analyses taken from the main shopping streets in the four UK towns and cities.

For all four UK cases, Figure 7 presents a two-step analysis from the inner ring road. It shows the degree of accessibility from the ring road to the encircled town centres. Coventry's ring road is badly connected to its centre while Bristol's ring road is well connected to all the shopping areas in the city centre. The Western part of Bristol's ring road is well connected to all streets in its vicinity, which gives the square on St. Augusts parade a high local catchment area. As a result, there are almost no people on the streets in the centre of Coventry in the evening, while Bristol's streets are full of nightlife activities. In Birmingham, some main shopping streets can be reached within two direction changes from the ring road. After the shops close, the streets are still perceived to be safe to walk through, while the remaining streets tend to be unsafe. The same can be said about Wolverhampton. The streets that cannot be reached within two direction changes from the ring road are considered to be unsafe in the evening. A feature of these streets is absence of people and they tend to be located in the 'dodgier' areas of Wolverhampton. 


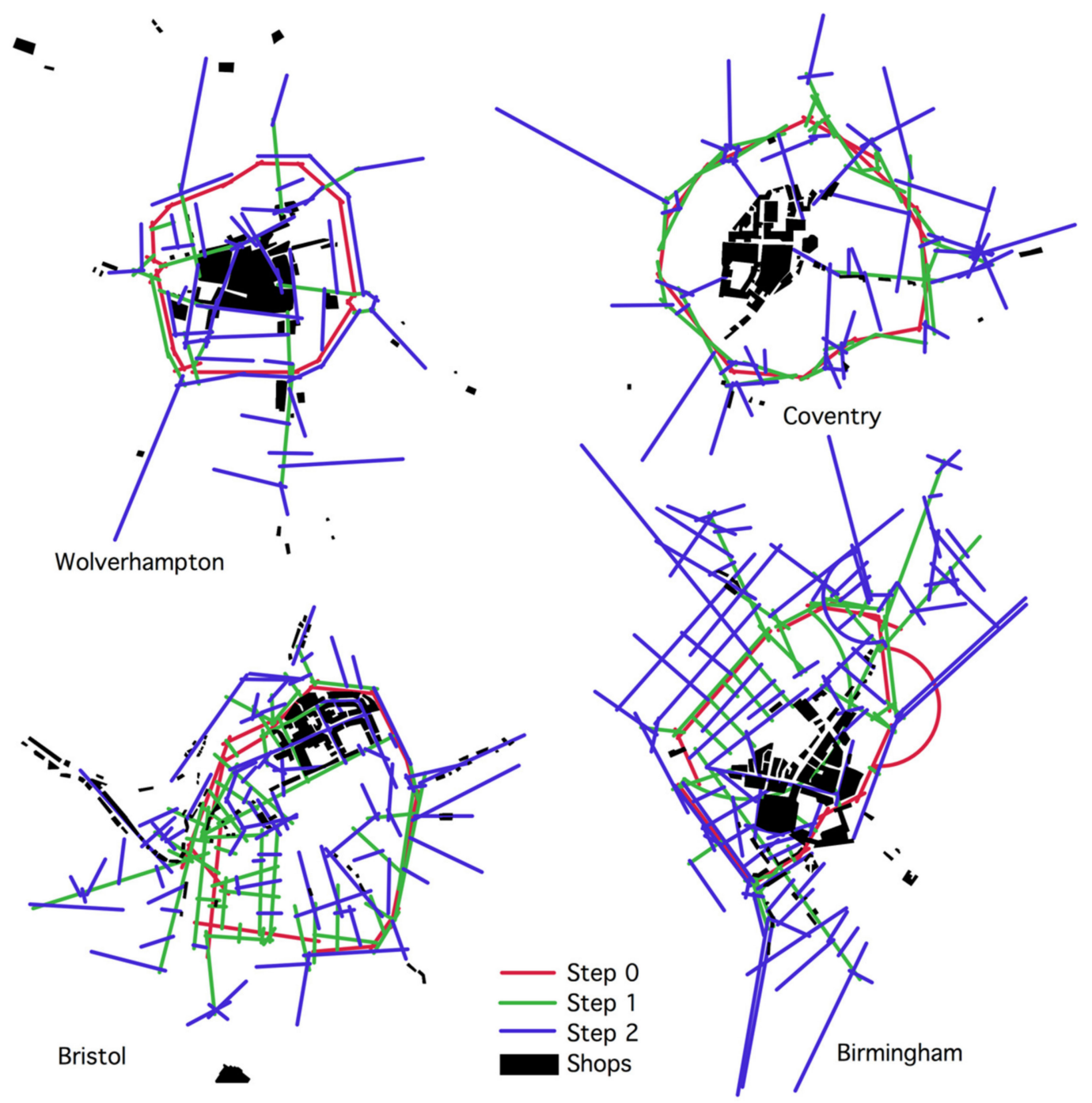

Figure 7. Two steps analyses taken from the four ring roads in the UK with the location pattern of shops.

\subsection{The Analyses of Atypical Cases-Mannheim and Tampere}

Similar studies were carried out in other European towns and cities with inner ring roads (Oslo, Tilburg, Mannheim, Eindhoven, and Tampere). The results comply with the four UK towns and cities cases: inner ring roads tend to segregate, to varying degrees, the central core they encircle. It all depends on the connectivity and visibility relationship between the centre and the ring road, and the type of street network the inner ring road is imposed upon.

In particular, the German town of Mannheim and the Finnish town Tampere are interesting atypical cases. Their inner ring roads are imposed upon a street network with a strict orthogonal grid pattern. This means that the topological distance is short, such that by only changing direction two times from the ring road, almost every street in the city centre can be reached.

As the model studies show in Figure 8, orthogonal street networks have a powerful effect on the dispersal of integration values. Consequently, a ring road should have almost no effect on the dispersal of integration values in central streets of built environments with orthogonal street networks. Even though a ring road slightly segregates its central core, the highest integration values still remain on a city's central streets. As can be seen below and on the top in Figure 8, the more broken up a street network is, the more the integration values are dragged towards the ring road. The natural grown city with an 
organic street pattern and a city consisting of several, but twisted, orthogonal grids tends to have a reduced level of spatial integration in their encircled cores as an effect of a ring road.

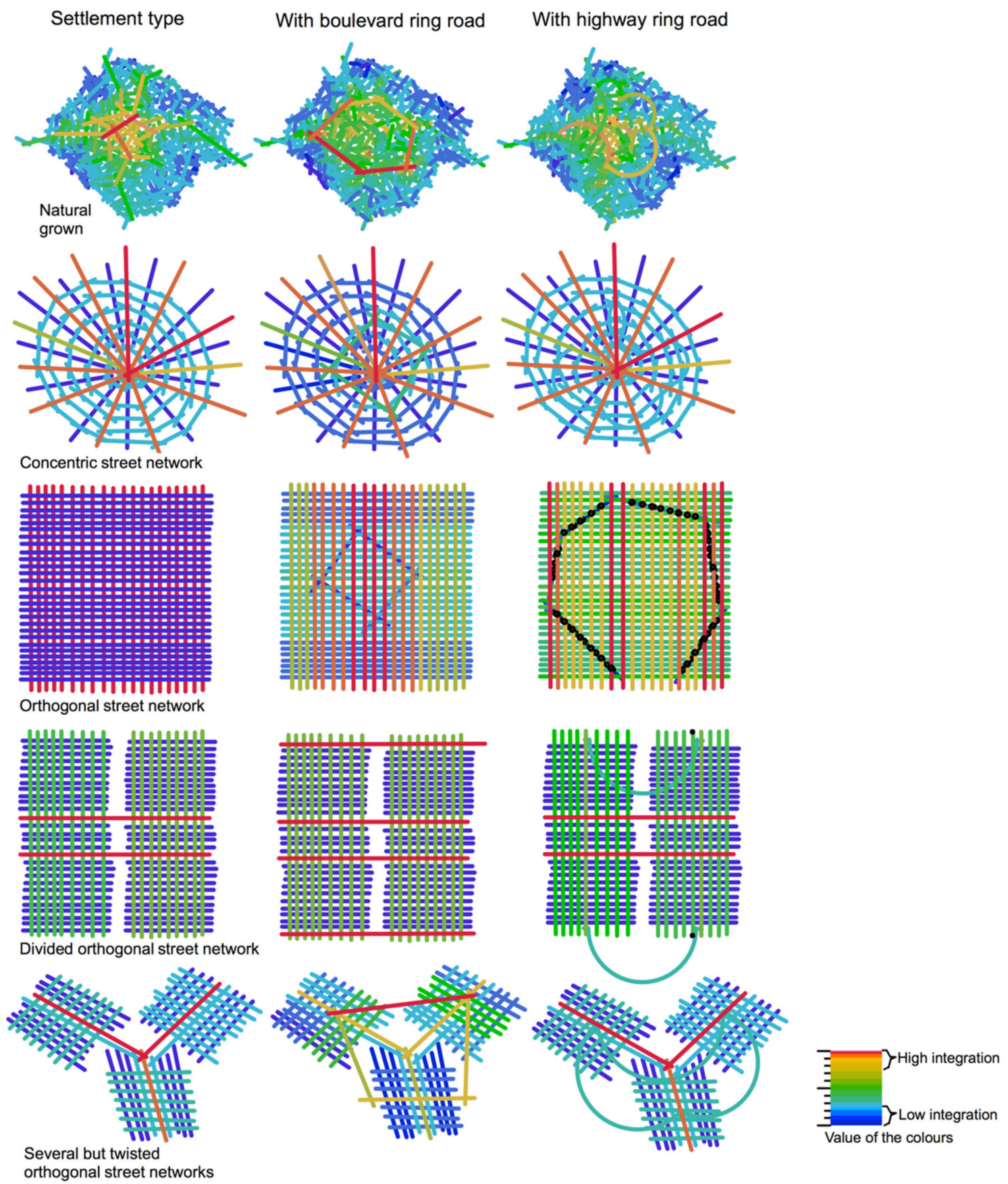

Figure 8. Model studies of ring roads imposed upon various types of street networks.

Finding a town or city with a ring road and a strict orthogonal grid is not easy. The closest example is Mannheim. The city's ring road was implemented more than 100 years ago, but parts of it were modernised in the 1960s and 1970s [29-31]. Mannheim's ring road, which does encircle the city centre is mostly in the style of a boulevard, but is in the form of a highway in its Western and Southern parts. Tampere represents the case of a ring road implemented on a divided orthogonal grid. The rapids divide the city [32]. The ring road in Tampere is well connected to the city centre in its Eastern and Western parts (boulevard standard), but badly connected in its Northern and Southern parts (highway standard). 
Figure 9 shows a spatial integration analysis of the street network (left) before and after the implementation of the ring road for Mannheim and the dispersal of building use (right). An unfortunate development makes Mannheim particularly interesting for the present research. The city was destroyed by war no less than three times, but its baroque orthogonal grid has remained since the plan of 1663 [30]. Most buildings are modern, but the old street network shapes their order. As can be seen in Figure 9, the city centre has high integration values before as well as after the implementation of the ring road. It implies that the orthogonal street network is a robust spatial system for which large new road projects can affect the location of existing shopping areas.

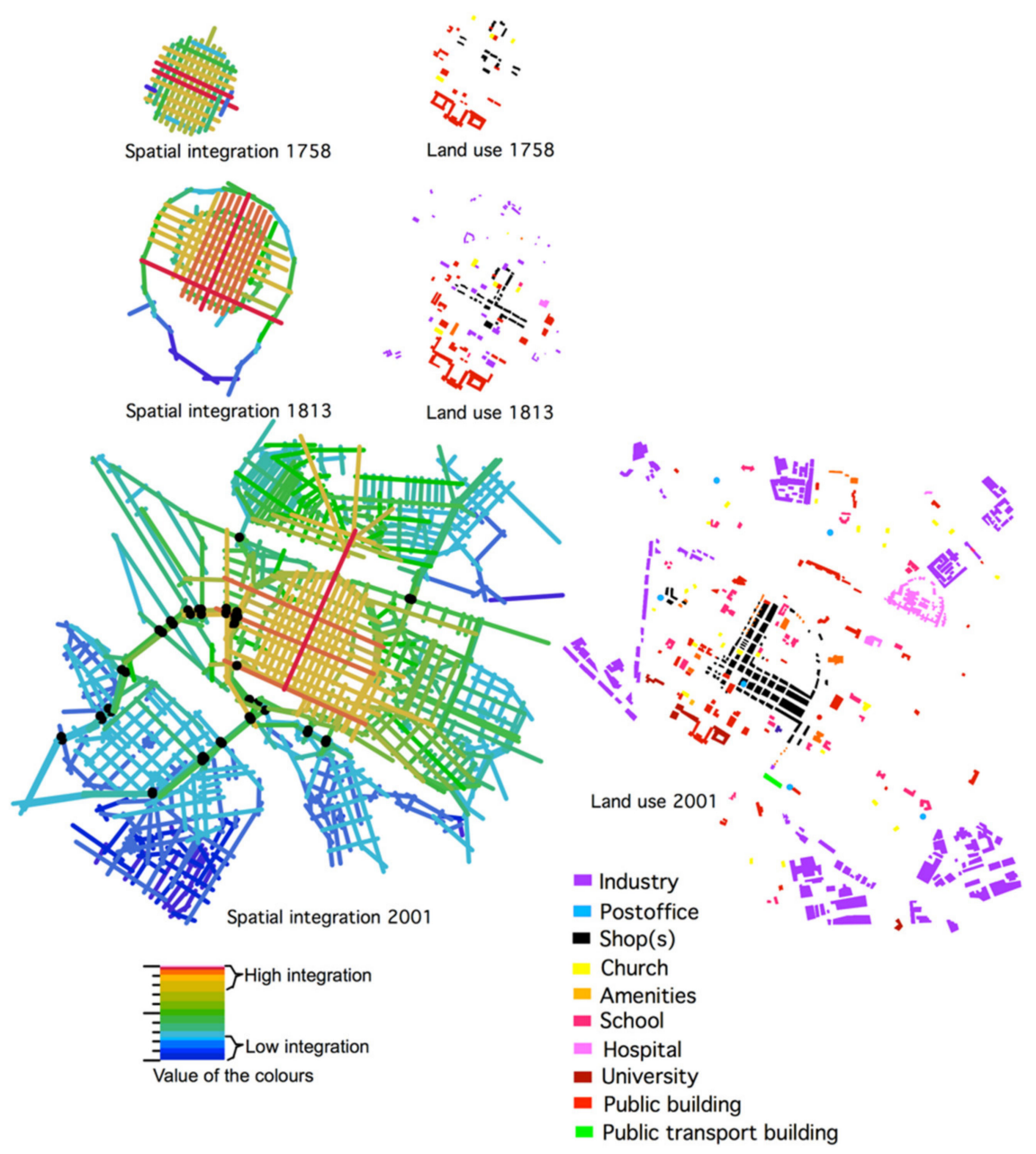

Figure 9. Integration analyses of Mannheim (left) with building use (right) before and after the ring road.

Figure 10 shows the spatial analyses (left) of the Finnish town of Tampere before and after the ring road and registrations of building use (right). Here again, the ring road did not affect the dispersal of integration values and the location pattern of shops in the city centre due to the divided orthogonal street pattern.

The studies of Mannheim and Tampere show that their ring roads did not affect the location pattern of shops. As can be seen in Figures 9 and 10, in both cases, it only changed from a linear to a convex location pattern. However, this development is not due to the ring road, but an effect of the pedestrianisation of main shopping streets. Shops that require car accessibility locate themselves in the closest parallel streets to the main shopping streets. 


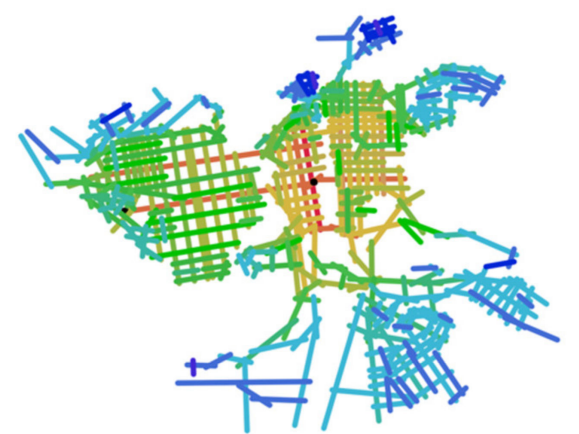

Spatial integration 1937

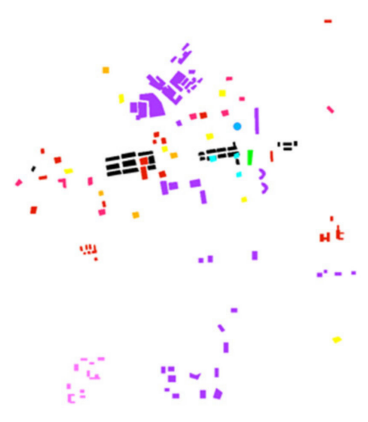

Land use 1937

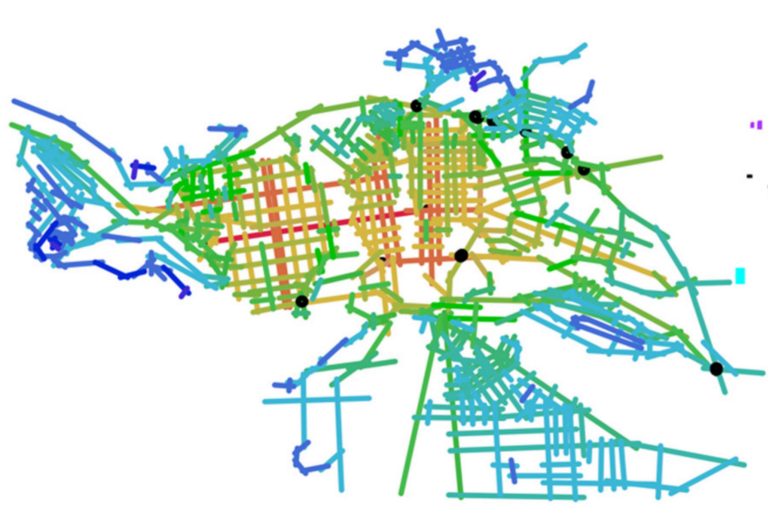

Spatial integration 2001

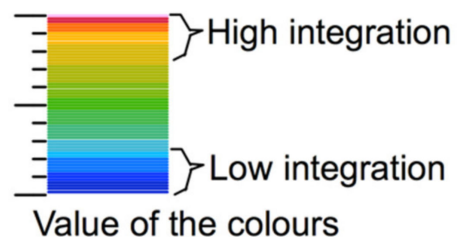

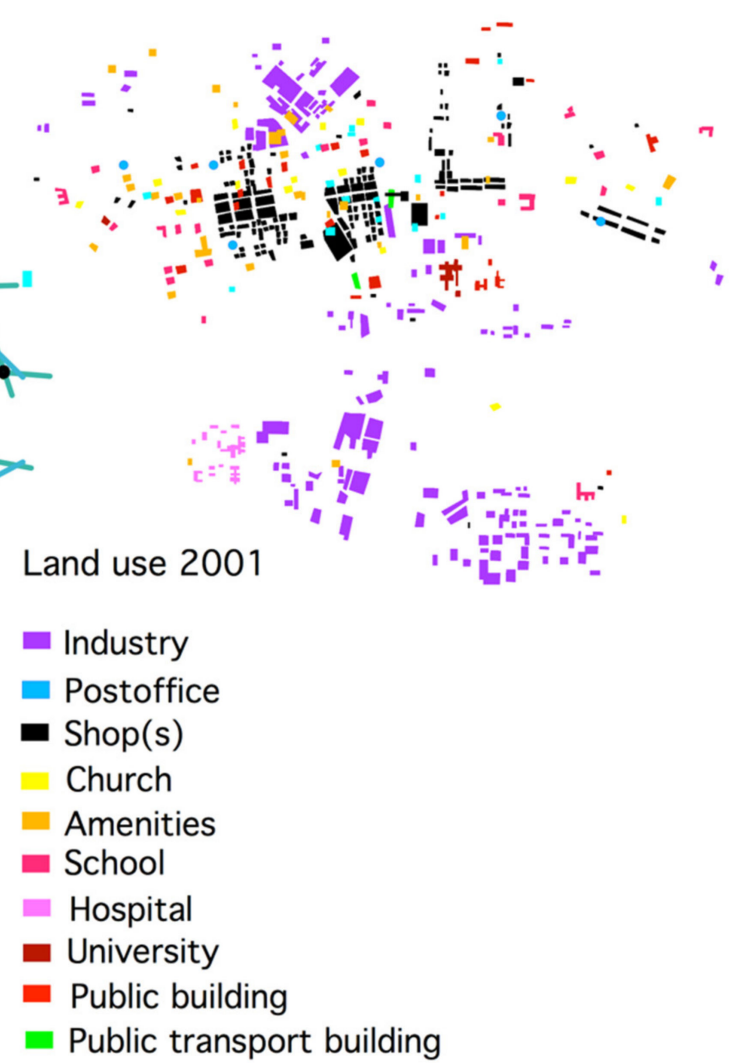

Figure 10. Integration analyses of Tampere with land use of buildings before and after the ring road.

When applying a two-step analysis on Mannheim and Tampere's ring roads, all streets in the town centres can be reached within a two times direction change from the ring road. As shown in Figure 11, it implies that the main shopping streets are located in the topologically and metrically most central areas in the centres, easily accessible from the ring roads. The use of space syntax makes it possible to offer explanations as to why ring roads have little effects on the dispersal of shops in cities with strict orthogonal street networks.

The more broken up the street network tends to be in central urban areas, the more the integration values tend to be dragged towards the ring road. Therefore, the structure of the street network on which a ring road is imposed plays a role in how the optimal location for shops will be affected. 

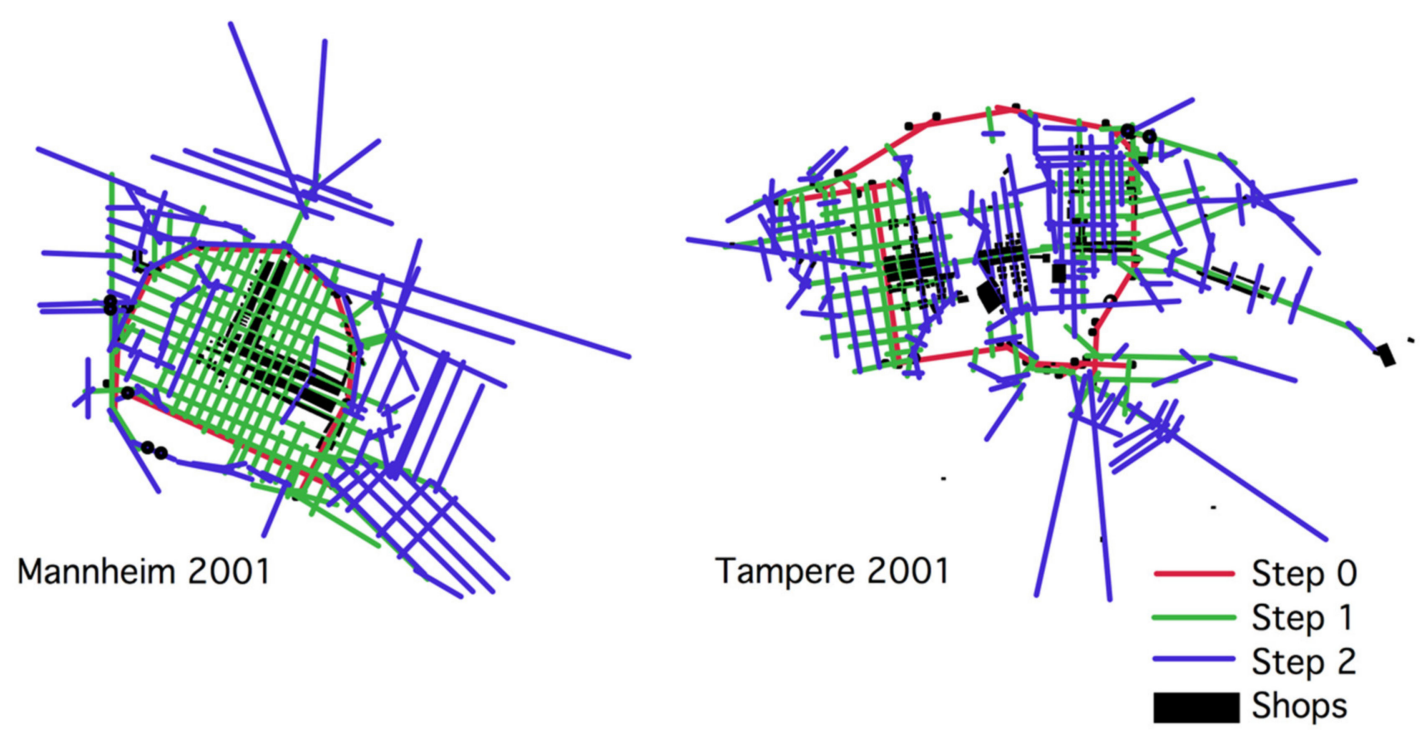

Figure 11. Two-steps analyses from Mannheim and Tampere's ring roads with the location pattern of shops.

\subsection{The Results' Relation to the Two Contradictory Views}

The analysis of Coventry, Wolverhampton, Birmingham, Bristol, Mannheim, and Tampere has shown that the location pattern of shops depends on the spatial configuration of the street network where human movement takes place. A successful shopping area requires a strategic position among the highest spatially integrated streets. Moreover, the shopping street needs to have a dense and well-connected street structure with a high number of interconnected streets in the vicinity in order to reach many potential customers within a short metric distance.

The street network's structure impacts whether the pattern of shops will get a linear or a clustered convex location pattern. According to the view presented in the Buchanan report, shops as such are attractors of urban movement. However, bad local street network conditions can favour a negative development such as the permanent closing of shops. This is the case with shops located in the shopping precinct of Coventry. The same holds for the Bull Ring shopping centre in Birmingham. It was closed down and demolished in 2001. Since 2001, Birmingham centre has undergone large urban renewals. The Bull Ring square is now reconnected with Birmingham's main shopping streets, and the ring road has mostly become a boulevard. The dangerous pedestrian subways are removed, and pedestrian crossings now occur at street level.

Regarding the relationship between road building and the distribution of shop and retail, all six case studies have provided evidence that do not falsify basic assumptions of the theory of the natural movement economic process. The space syntax method has managed to describe how ring roads affect town and city centres regarding the pattern of shops and the spatial configuration of the street network in different town and cities.

A highway standard of a ring road tends to separate the peripheral areas of a city from the centre. This increases the number of direction changes between the streets located in the peripheral area and the city centre. Shops located in the peripherals areas and along streets inside a ring road that lose the extension of their local catchment area tend to close down. Most main shopping streets located inside a highway standard ring road tend to exhibit a more compact distribution of shops. These kinds of town centres consist of larger shopping centres where several shops can be reached at a short distance from each other.

On the other hand, a boulevard standard of a ring road contributes to keeping the connection between the outside streets and the city centre. The situations of the squares Bull Ring in Birmingham and St. Augustin's parade in Bristol have one thing in common; the ring road was built right through these shopping areas. In the case of Birmingham, the highway shaped ring road cut off the connections between the shopping street and the 
centre and it also reduced the topological and metric extension of Bull Ring. In the case of Bristol, the boulevard part of the ring road did not affect the shopping area at all at St. Augustin's parade.

As it turns out, ring roads can spatially segregate their encircled city centres to different degrees. This seems to depend on the degree of a ring road's connectivity and on the type of street network on which it is imposed, and how accessible and visible the city centre is from the ring road. The way a ring road affects the pattern of shops depends on a its effect on the local street network conditions for a shopping area. The same holds true for the dispersal of integration value changes. The centre of Coventry is a centre planned with the purpose to separate pedestrian and car traffic movement. The result is not just an effect of the ring road, but of a separation of movement routes such that visibility and adjacency do not correlate well with natural movement patterns for pedestrians.

For a shopping street's local street network conditions, the following results were obtained: if the ring roads cut off their extension, then it is probable that the location pattern of shops changes from a linear to a convex pattern. Shops tend to disappear along streets losing their topological and metric central position in an urban area. Likewise, if the number of streets reduces within a short metric distance from the main shopping street, shops tend also to close down. If the number of streets and the number of possible movement routes increase in a short metric distance from a shopping street, then the pattern of shops tends to be more clustered together. In these areas, larger successful shopping centres tend to be located. This is the case of Dudley street in Wolverhampton and Broad Mead street in Bristol.

For a statistical comparison, the correlation coefficient (R2) between global integration and street connectivity is taken from all the spatial analyses of the six towns and cities. According to Bill Hiller, this correlation coefficient shows the degree of 'intelligibility' of a settlement. The higher values on the R2, the higher degree of orientability of a settlement [33]. As can be seen from Table 1, the inner ring road had the largest impact on the centres of Coventry and Birmingham. Both centres lost the degree of orientability after the implementation of the ring road. This has a large impact of the economic vitality of the city centres, which likely contributed to the proposal and implementations of new urban regeneration plans for these two urban centres after the millennium. Conversely, the ring roads of Wolverhampton and Bristol contributed to an increase in the orientability of their city centres. Here, the ring road contributed to a slight increase in the accessibility to several shopping streets in the city centre. Some shopping streets that are easily accessible from the ring road increased their integration values.

Table 1. Correlation between global integration and street connectivity.

\begin{tabular}{ccc}
\hline Town or City & R2 before the Ring Road & $\begin{array}{c}\text { R2 after the Ring Road } \\
\text { (Vehicle Routes) }\end{array}$ \\
\hline Coventry & 0.6580 & 0.2715 \\
Wolverhampton & 0.2520 & 0.2657 \\
Birmingham & 0.4146 & 0.2867 \\
Bristol & 0.2499 & 0.2946 \\
Mannheim & 0.2947 & 0.2005 \\
Tampere & 0.3091 & 0.2447 \\
\hline
\end{tabular}

For Mannheim and Tampere, the ring road contributed to a slight reduction of the degree of orientability in their city centres. Even though Mannheim and Tampere main shopping streets obtain the highest integration values after the implementation of the ring road, the ring road has still contributed to a slight reduction of the integration values of these shopping streets. All the R2 values that are reduced are coloured in red in Table 1. Clearly, the larger reductions of the R2 values, the larger the location pattern of shops were affected by spatial configurative changes of the street and road networks. This is the case for Coventry and Birmingham. 
In all six cases, the ring road contributed to the largest changes in the street and road network system. There were some alterations of other streets in the city centres, but they are all related to the implementation of the ring roads. When the inter-connectivity of shopping streets is improved due to the inner ring road, the number of shops increases. Regarding the economic vitality of shops, future studies could focus on sales numbers from shops in the vicinity of inner ring roads before and after implementation. Naturally it depends on data availability.

What are then the limitations of the space syntax method? Even though space syntax is constantly developing, one has to be aware of its limitations. Space syntax cannot analyse place identity, building morphologies, and street pattern. The method's focus is only on quantifying the spatial interrelationship of street structures. So far, space syntax only calculates one- and two-dimensional spatial relationships, but not three-dimensional spatial relationships. Bridges and tunnels are solved through the unlink lines function in the space syntax software. There are current developments going on for making three dimensional spatial analyses methods [34]. The purpose is to apply these methods on urban centres where movement flows takes place on several levels. The CBD area in Hong Kong is used as a test case [35].

\section{Conclusions: Road Building and Vital Shopping Streets in City Centres}

The construction of an inner ring road has a comprehensive impact on a city's spatial structure and socio-economic activities. Therefore, the space syntax method can be useful to predict certain kinds of consequences of new road projects on existing urban centres. The spatial analysis of a street network seen together with the pattern of land uses offers a rather detailed understanding of how larger road projects affect urban areas and land-use in their vicinity as well as in town centres. The space syntax method can identify the spatial configurative changes, while the registration of socio-economic activities can confirm the spatial configurative explanations. Until now, a systematic understanding of changes in spatial integration can offer the best explanation of the possible effects of road building on the location pattern of shops of city and town centres.

The present investigation was concerned with the question; what happens after a ring road's implementation? At least in this respect, it was possible to set forth some general statements as to how road building affects the location pattern of shops and retail areas. Shops locate themselves along the highest spatially-integrated streets in order to reach as many potential customers as possible. If a ring road or other large road projects reduce the spatial integration of this optimal location, shops will relocate. Moreover, the results from this inquiry strengthen the theory of the natural movement of economic processes. Thus, the spatial configuration of the street and road network impacts the location pattern of shops. Applying space syntax on future road plans is, thus, able to explain the impacts of how each proposed alternative will affect the economic centres in built environments. Hence, future road planning can account for the relationship between spatial configurative changes of the street network and changes in optimal locations for shops.

This contribution shows clearly that the space syntax method can be used for testing out how various planning proposals of new roads will affect the location pattern of shops of existing town and city centres down at the street level-whether it will be pedestrianor car-based, and whether the accessibility and economic vitality of the urban centre will increase or decrease. This knowledge is needed to steer urban transformations in such a way for reaching sustainability development goal number 11: achieving sustainable cities and communities.

How, then, can an inner ring roads revitalise urban centres? Seemingly, the idea to divert through traffic away from town and city centres can be done successfully. As the case studies of Wolverhampton and Bristol show, the ring road needs to be well-connected to all adjacent streets both inside and outside the ring and the main shopping streets need to be reached within a two times direction change. Highway standards on the inner ring roads and pedestrian subways should be avoided. Space syntax was applied on the 
Norwegian town Tønsberg in 2003. The public road administration proposed various road alternatives to lead through traffic away from the town centre. When the analyses of these alternatives were presented for the politicians, they confirmed that there was a pressure from investors who wanted to buy up land for building out-of-town shopping centres at the most integrated junctions [22]. Likewise, space syntax was also applied on evaluating the impact of various road proposals for making a new connection between the highways A4 and A44 on shopping centres in the Dutch town of Leiden. As it turns out, the shop owners in one shopping street feared a loss of income due to a reduction of integration for one of the alternatives [23]. Therefore, the spatial structure of the street and road network matters as drivers for the location pattern of shops in town and city centres. This information supports the findings from this inquiry and shows that space syntax is useful for evaluating how new road proposals affect the accessibility to shopping streets of existing well-functioning town and city centres. As it turns out, centrality is not a state but a dynamic process. Changes of the spatial configuration of the street network can affect the locations of urban centres, whether they fade away of new ones emerges in towns and cities.

The present research does not provide an answer as to how to plan roads in urban areas. It contributes to an explanation on how new roads affect the urban street network on which they are imposed and, thus, the economic-related land-use realised within this structure on which they are imposed. Besides, this research sheds some light on how crucial the role of the road engineer is in urban development. As research has shown, the spatial structure of the street and road network matters for the vitality of shopping areas in town and city centres $[36,37]$. Even though the road engineers are acting on the behalf of the government, their proposed solutions are making the necessary spatial framework for the socio-economic life in built environments. It all depends on how new road-links segregate, integrate, connect, or disconnect the urban areas they are imposed upon. It all depends on various degrees of spatial integration, connectivity, and accessibility. The effect of the relevant kind of changes can be explained in terms of changes in the location pattern of shops and retail whether they tend to fade away or increase.

Funding: This research received no external funding.

Institutional Review Board Statement: Not applicable.

Informed Consent Statement: Not applicable.

Data Availability Statement: Data sharing not applicable.

Conflicts of Interest: The author declares no conflict of interest.

\section{References}

1. Van Nes, A. Road Building and Urban Change. The Effect ff Ring Roads on The Dispersal of Shop and Retail in Western European Towns and Cities. Ph.D. Thesis, Department of Land Use and Landscape Planning, Agricultural University of Norway, Ås, Norway, 27 September 2002.

2. Fwa, T.F. The Handbook of Highway Engineering; Taylor \& Franscis group: London, UK, 2006.

3. Falleth, E.; Kollbotn, K.; Tombre, E. Land Use Development along By-Pass Roads; Technical Report; NIBR: Oslo, Norway, 1995.

4. Alonso, W. Location theory. In Regional Development and Planning: A Reader; Friendman, J., Alonso, W., Eds.; M.I.T Press: Cambridge, MA, USA, 1964; pp. 78-106.

5. Kostof, S. The City Shaped: Urban Patterns and Meanings through History; Thames and Hudson Ltd.: London, UK, 1991.

6. The Corporation of Glasgow. Interim Report on the Glasgow Inner Ring Road; Glasgow Corporation Printing and Stationary Department: Glasgow, UK, 1962.

7. Button, K.J.; Pearman, A.D.; Fowkes, A.D. Car Ownership. Modelling and Forecasting; Gower Publishing Limited: Hampshire, UK, 1982.

8. Ministry of Transport. Traffic in Towns. The Specially Shorted Edition of the Buchanan Report; Penguin Books: Middlesex, UK, 1963.

9. Beekman, B. Eindhoven Stadsontwikkeling 1900-1960; Beekman: Mierlo, The Netherlands, 1982.

10. SCAFT Rapporten. Riktlinjer För Stadsplanering Med Hensyn Till Trafikksäkerhet; Statens Planverk Vägverk: Stockholm, Sweden, 1968.

11. ASVV. Aanbevelingen voor Verkeersvoorzieningen Binnen de Bebouwde Kom; CROW: Ede, The Netherlands, 2004. 
12. Lemke, K. The new german highway capacity manual (HBS 2015). Transp. Res. Procedia 2016, 15, 26-35. [CrossRef]

13. Department for Transport. Manual for Streets; Thomas Telford Publishing: London, UK, 2007.

14. Hillier, B. Centrality as a process: Account for attraction inequalities in deformed grids. Urb. Des. Int. 1999, 4, 107-127. [CrossRef]

15. Hillier, B. Space Is the Machine; Cambridge University Press: Cambridge, UK, 1996.

16. Hillier, B.; Penn, A.; Hanson, J.; Grajewski, T.; Xu, J. Natural movement: Or, configuration and attraction in urban pedestrian movement. Environ. Plan. B 1993, 20, 29-66. [CrossRef]

17. Van Nes, A.; Yamu, C. Exploring challenges in space syntax theory building: The use of positivist and hermeneutic explanatory models. Sustainability 2020, 12, 7133. [CrossRef]

18. Hillier, B.; Turner, A.; Yang, T.; Park, H.T. Metric and topo-geometric properties of urban street networks. In Proceedings of the 6th International Space Syntax Symposium, Istanbul, Turkey, 12-15 June 2007.

19. Hillier, B.; Yang, T.; Turner, A. Normalising least angle choice in Depthmap and how it opens up new perspectives on the global and local analysis of city space. J. Space Syntax 2012, 3, 155-193.

20. Hillier, B.; Hanson, J. The Social Logic. of Space; Cambridge University Press: Cambridge, UK, 1984.

21. Lilleslett, S.; Ladehaug, K.; van Nes, A. The effects of new bypass roads on small Norwegian towns. Space syntax and land use analyses of Jessheim, Askim, Gol and Hokksund. In Proceedings of the 12th International Space Syntax Symposium, Beijing, China, 8-12 July 2019.

22. Van Nes, A. The use of space syntax in impact assessment. In Proceedings of the AESOP Conference, Leuven, Belgium, 9-12 July 2003.

23. Van Nes, A. Centrality and development in the Rijnland region, In Proceedings of the 6th International Space Syntax Symposium, Istanbul, Turkey, 12-15 June 2007.

24. Van Nes, A. Typologies of shopping areas in Amsterdam. In Proceedings of the 5th International Space Syntax Symposium, Techne Press, TU-Delft, Delft, The Netherlands, 13-17 June 2005.

25. Richardson, K. Twentieth-Century Coventry; MacMillan: London, UK, 1972.

26. Punter, J.V. Design Control in Bristol 1940-1990; Redcliffe Press Ltd.: Bristol, UK, 1990.

27. Rogers, R. Towards an Urban Renaissance, Urban Task Force; E \& FN Spon: New York, NY, USA, 1999.

28. Jenks, M.; Burton, E.; Williams, K. The Compact City. A sustainable Urban Form? E \& FN Spon: New York, NY, USA, 1996.

29. Caroli, M.; Teutsch, F.; Petrzilka, E.; Schenk, A. Mannheim im Aufbruch. die Stadt an der wende vom 19. Zum 20. Jahrhundert, Kleine Schriften des Stadtarchivs Mannheim; Verlagsbüro von Brandt: Mannheim, Germany, 1999.

30. Keller, V. Streiflichter aus Alt.-Mannheim; Sutton Verlag: Erfurt, Germany, 2000.

31. Rings, H. Das grüne Quadrat. Mannheimer Stadtgrundriss und Bild im Vormärz (1815-1848) Impressionen, Mannheimer Geschichtsblätter, Neue Folge no. 7/2000, Verlag; Regionalkultur: Mannheim, Germany, 2000. (In German)

32. Jokela, A.; Kirjavainen, K.; Kirjavainen, M.; Martikainen, H.; Rasila, V.; Seppälä, J.; Tuominen, T. Tampere Finland; Tampere-Seuran: Tampere, Finland, 1990.

33. Penn, A. Exploring the frontiers of space: Bill Hiller (1937-2019). Urban Morphol. 2020, 24, 224-229.

34. Yanru, H.; Masoudi, M.; Chadala, A.; Olszewska-Guizzo, A. Visual quality assessment of urban scenes with the contemplative landscape model: Evidence from a compact city downtown core. Remote Sens. 2020, 12, 3517. [CrossRef]

35. Bruyns, G.; Nel, D.; Higgens, C.D.; van Nes, A. Flat versus volumetric methodologies. Restructuring spatial analysis and other indices. In Proceedings of the 12th International Space Syntax Symposium, Beijing, China, 8-12 July 2019.

36. Van Nes, A.; Berghauser Pont, M.; Mashhoodi, B. Combination of space syntax with spacematrix and the mixed use index. In Proceedings of the 8th International Space Syntax Symposium, Santiago de Chile, Chile, 3-6 January 2012.

37. Ye, Y.; van Nes, A. Quantitative tools in urban morphology: Combining space syntax, spacematrix and mixed-use index in a GIS framework. Urban Morphol. 2014, 18, 97-118. 